\title{
El adolescente infractor: de menor a pandillero
}

\section{María Consuelo Barletta Villarán}

La adopción de la Convención sobre los Derechos del Niño, por las Naciones Unidas en noviembre de 1989, y su posterior ratificación por los Estados, ha originado la derogación de leyes preexistentes y el cambio del rol del Estado, en el tratamiento de problemáticas vinculadas al niño y a la familia.

Realizando un balance general del significado de la vigencia de la Convención en nuestra legislación, debemos reconocer que han existido grandes avances a nivel legislativo, que han brindado un marco jurídico adecuado para el tratamiento del niño como sujeto de derechos, pero estos progresos han estado acompañados de retrocesos, que han significado la vuelta a la doctrina previa a la Convención.

Confirmamos lo antes dicho, al dar lectura a los decretos legislativos $N^{\circ} 895$ y No 899 referidos a la "Ley de Terrorismo Agravado" y a la «Ley de Pandillaje Pernicioso» respectivamente, siendo el segundo materia del presente trabajo. Ambos textos legales, han transgredido las obligaciones asumidas por el Estado peruano al ratificar la Convención.

Para el abordaje de esta temática, quisiéramos rescatar tres cuestiones fundamentales. En primer lugar, vamos a hacer referencia al objetivo de la legislación en análisis; en segundo lugar, veremos como la promulgación de la Ley de Pandillaje Pernicioso ha violado las normas y principios contenidos en la Convención sobre los Derechos del Niño; y para concluir, plantearemos una propuesta para brindar seguridad ciudadana sin transgredir los derechos reconocidos a los adolescentes que infrinjen la ley. 


\section{Análisis comparativo con la legislación de menores}

Conforme lo indicaba el D. Leg. No 899 , el objetivo estratégico de esta ley es brindar seguridad nacional. Este tema no es nuevo en el tratamiento de los menores de edad que infrinjen la ley. Revisando las conclusiones de los Congresos Panamericanos de la Infancia, ${ }^{1}$ comprobamos que en el período de 1942 a 1968 los Estados buscaron dar solución a una preocupación, entonces constante, que consistió en propiciar estabilidad y seguridad nacional a nivel interno y externo, respondiendo así a la situación de incertidumbre, generada por las post-guerras mundiales. Como consecuencia de ello, los discursos en los Congresos Panamericanos focalizaron su interés en un sector de la infancia, aquellos que escapaban del control socio-familiar, haciéndose en consecuencia destinatarios del estigma de "menores peligrosos».

Este pensamiento reforzó el control socio-penal encubierto, ya vigente en las legislaciones de menores de Latinoamérica, desde las primeras décadas del siglo veinte. Es así que con un discurso proteccionista - asistencialista, se justificó la intervención del juez de menores, cumpliendo un rol supletor de las políticas sociales. ${ }^{2}$

De esta manera, la respuesta estatal se caracterizó por la aplicación de medidas correctivas excesivas, teniéndose al internamiento como la medida privilegiada, por ser necesario proteger al Estado contra este enemigo interno, "los menores», quienes amenazaban la seguridad nacional. Las llamadas "medidas de protección" cumplieron esta función, aplicándose indiscriminadamente tanto a los menores en situación irregular como a los que infrinjían la ley.

Cuando damos lectura a la Ley de Pandillaje Pernicioso, recordamos la legislación de menores y verificamos cómo se ha focalizado esta visión socio-jurídica del menor como sujeto peligroso en los adolescentes integrantes de pandillas, por lo cual, corresponde aislarlo por un período más o menos largo a través de la medida socioeducativa de la internación. En consecuencia, respondiendo al estereotipo ya creado que la pertenencia a una pandilla lo hace difícilmente recuperable,

1 Donde participaron representantes de los Estados, entre ellos del Perú, para discutir los derechos y las políticas a favor de los entonces llamados menores.

2 En nuestro país, el Código de Menores de 1962 plasmó a plenitud esta doctrina, habiendo tenido como antecedente inmediato el Código Penal de 1924. 
se busca privilegiar la medida de reclusión del pandillero en un Centro Juvenil, sin ninguna medida alternativa viable, de cumplimiento en libertad. Así, el resguardo de la seguridad nacional (o ciudadana) se hace prevalecer sobre los derechos de los adolescentes infractores, derechos que le corresponden por su condición natural de sujetos en desarrollo.

\section{El efecto vinculante de la Convención sobre los Derechos del Niño}

La Convención sobre los Derechos del Niño, a diferencia de los instrumentos internacionales que con anterioridad trataron la temática ${ }^{3}$, tiene un carácter obligatorio para los Estados partes que han procedido a su ratificación. Sobre el particular, Mercedes Carreras plantea lo siguiente:

«La naturaleza jurídica de la Declaración y de la Convención difiere sustancialmente, y lo mismo cabe decir de su fuerza ante los Estados para que se cumplan. Este tipo de declaraciones, en su función de instrumento internacional, constituye lo que se llama "Derecho suave" (soft Law) [...] no obliga a los Estados y constituye una mera definición del pensamiento de las Naciones Unidas respecto a los derechos del niño. Mientras que las Convenciones son el "Derecho Fuerte" (hard Law) y por su carácter obligatorio requieren de una decisión activa de los Estados [...] garantizar los derechos inclú́dos en ella y a introducir en su legislación los derechos que se han formulado [...] incluyen mecanismos para arbitrar su cumplimientom. ${ }^{4}$

3 Los instrumentos internacionales que precedieron la Convención sobre los Derechos del Niño tuvieron un carácter declarativo, siendo orientador pero no obligatorio para los Estados. Entre estos institumentos encontramos: La Declaración de Ginebra (1924), La Declaración Universal de los Derechos del Niño (1959), Las Reglas Mínimas de las Naciones Unidas para la Administración de Justicia de Menores - Reglas de Beijing (1985), Reglas de las Naciones Unidas para la protección de los menores privados de libertad (1991) y las Directrices de las Naciones Unidas para la Prevención de la Delincuencia Juvenil.

4 Mercedes Carrera. «Los Derechos del Niño: De la Declaración de 1959 a la Convención de 1989».en: Derechos Humanos, Tecnos. Madrid, 1992. p.192. 
En consecuencia, debido al carácter vinculante de la Convención, el Estado peruano ${ }^{5}$ ha asumido, en síntesis, las siguientes obligaciones:

\subsection{Respetar y garantizar la Convención sobre los Derechos del Niño}

La racionalidad jurídica del «deber de respetar», consiste en evitar que el Estado y sus agentes transgredan las normas contenidas en este instrumento internacional, que en síntesis contiene los derechos humanos de los niños. ${ }^{6}$

El «deber de garantizar», implica un rol activo del Estado, caracterizado por la ejecución de las acciones necesarias para lograr que todos los niños de su jurisdicción sean sujetos de derechos, es decir, que tengan capacidad de goce y de ejercicio. El Estado deberá establecer los mecanismos requeridos para el reclamo de la vulneración de un derecho contenido en la Convención.

En la Convención sobre los Derechos del Niño, se recoge explícitamente esta obligación, cuando se indica: «Los Estados partes [...] respetarán los derechos enunciados en la presente Convención, y asegurarán su aplicación a cada niño sujeto a su jurisdicción, sin distinción alguna, $[\ldots] »{ }^{7}$

En el ámbito penal, el Estado peruano dando cumplimiento a su deber de respetar la Convención, recogió en el Código de Niños y Adolescentes (actualmente derogado por los decretos legislativos en discusión) la garantía del internamiento como última medida, considerando una internación para el adolescente infractor no mayor a tres años y otorgando a la discrecionalidad del juez la posibilidad de aplicar las medidas socioeducativas alternativas.

5 El Estado peruano procede a su ratificación mediante Resolución Legislativa $N^{\circ}$ 25278 del 3 de agosto de 1990.

$6 \mathrm{Al}$ referimos a derechos humanos conviene que rescatemos su expresión como: «...derechos fundamentales de la persona humana. Con ello se quiere manifestar que toda persona posee derechos por el hecho de serlo y que éstos deben ser reconocidos y garantizados por la sociedad, sin ningún tipo de descriminación social, económica, cultural o sexual...existe un derecho fundamental para el hombre, base y condición de todos los deinás: el derecho a ser reconocido siempre como persona humana."

Máximo Pacheco. Los Derechos Fundamentales de la Persona Humana en Estudios Básicos de Derechos Humanos II.Instituto Insteramericano de Derechos Humanos. T.II. San José de Costa Rica. 1995 p.67.

7 Artículo 2 de la Convención Internacional sobre los Derechos del Niño. 
A manera de ejemplo, entre los mecanismos que el Estado incorpora en la legislación, a fin de brindar resguardo a los derechos de los niños y adolescentes, tenemos la acción de Hábeas Corpus, donde se reconoce al niño o adolescente el derecho a impugnar la orden que lo ha privado de libertad ${ }^{8}$.

\subsection{Adoptar las medidas para hacer efectiva la Convención sobre los Derechos del Niño}

Obligación contenida en la Convención, que indica: «los Estados partes adoptarán todas las medidas administrativas, legislativas y de otra índole, para dar efectividad a los derechos reconocidos en la presente Convención».?

Este deber no se limita a la incorporación de las normas internacionales o en la reproducción de las mismas en la legislación interna (eliminándose las discrepancias que pudieran existir con lo contenido en la Convención), sino que adicionalmente se genera en los Estados partes la obligación de diseñar y ejecutar políticas sociales orientadas a la superación de la pobreza, a través de la consecución de la igualdad de oportunidades.

Para dicho efecto, las Directrices de las Naciones Unidas para la prevención de la Delincuencia Juvenil, (Directrices de Riad), orientan a los Estados en la implementación de políticas sociales, que favorezcan la prevención de actos delictivos por menores de edad, considerándose que la preocupación y el interés primordial de la temática radica en la ejecución de medidas preventivas de la delincuencia juvenil, como parte esencial de la prevención del delito en la sociedad.

Las recomendaciones contenidas en las Directrices tienen como postulado el papel primordial que deben ejecutar los jóvenes como actores sociales, inspiradas en los principios de la Convención que buscan erradicar la actitud paternalista, de control o socialización por parte de los agentes estatales para con el niño o adolescente.

Para la consecución de estos objetivos, se ha de plantear, como estrategia, la formación de la personalidad del niño, debiendo el gobierno de turno formular a todos los niveles planes generales de pre-

8 Artículo $199^{\circ}$ del Texto Unico Ordenado del Código de Niños y Adolescentes.

9 Artículo $4^{\circ}$ de la Convención Internacional sobre los Derechos del Niño. 
vención, en donde el diagnóstico, la coordinación entre organismos públicos y privados, la estrecha vinculación intersectorial y la participación de los jóvenes son los pilares de cualquier gestión.

El objetivo de estos programas, como lo indican las Directrices de Riad, no debe ser otro que favorecer la socialización e integración de los niños o adolescentes, utilizando espacios socializadores como la familia, la comunidad, los grupos de jóvenes que se encuentran en condiciones similares, la escuela, la formación profesional y el medio laboral. Debiendo ser concordante con el objetivo fundamental de la integración del niño y adolescente en el seno de su familia y comunidad, la política criminal del gobierno, cual deberá estar orientada a la consideración del internamiento como última medida.

\subsection{Obligación del Estado de cooperar con la supervisión internacio- nal}

Esta obligación tiene su origen en el principio del Derecho Internacional que obliga a los Estados partes a cumplir los tratados de buena fe. Específicamente, comprende el deber de brindar información sobre las medidas adoptadas por el gobierno, para dar cumplimiento a la Convención.

Debiendo asumir el Estado que el conjunto de derechos contenidos en este instrumento internacional, conforman lo mínimo exigible para los Estados partes, al respecto Cecilia Medina ${ }^{10}$ afirma: $«[. .$.$] nada$ autoriza a que el Estado lo restrinja y nada obsta o más bien todo alienta para que agregue otros derechos en su ordenamiento jurídico nacional», facultad que ha venido en denominarse "progresividad». ${ }^{11}$

La Convención además de su efecto vinculante tiene rango constitucional. El reconocimiento de este nivel jerárquico, negaba la posi-

10 Cecilia Medina. El Derecho Internacional de los Derechos Humanos. En Sistema Jurídico y Derechos Humanos. Sociedad de Ediciones de la Universidad Diego Portales. Santiago, 1996.p.32

11 "Como los derechos humanos son inherentes a la persona y su existencia no depende del reconocimiento de un Estado, siempre es posible extender el ámbito de la protección a derechos que anteriormente no gozaban de la misma. Una manifestación de esta particularidad la encontramos en una disposición que, con matices, se repite en diversos ordenamientos constitucionales, según la cual la enunciación de derechos contenida en la Constitución no debe entenderse como negación de otros, que siendo inherentes a la persona humana, no figuren expresamente en ella. 
bilidad de cualquier transgresión a la misma; más aún, al ser un tratado de derechos humanos no cabía la posibilidad de negar con la promulgación de una norma posterior, los derechos humanos ya reconocidos con este instrumento internacional.

\section{El adolescente infractor como sujeto con derechos y garantías}

Debemos partir del análisis de que el principio fundamental que atraviesa la Convención: la visión sociojurídica del niño (entiéndase también adolescente) como sujeto de derechos, cambió y, junto con ella, la del adolescente infractor de ley. Este adolescente es también sujeto de derechos, condición que se manifiesta en el otorgamiento legal de garantías sustantivas ${ }^{12}$ y procesales, las generales que pertenecen a toda persona incursa en un proceso penal ${ }^{13}$ y las específicas que les son propias por encontrarse todavía en formación su personalidad. ${ }^{14}$

Estas garantías son reconocidas, en su totalidad, en el artículo $205^{\circ}$ del Texto Único Ordenado del Código de Niños y Adolescentes. Sin embargo esto se contradice con el tratamiento que recibe el adolescente pandillero, en el mismo texto legal, el cual dista de lo establecido por la Convención sobre los Derechos del Niño.

La Convención sobre los Derechos del Niño destierra la concepción del menor infractor como sujeto inimputable, reconociéndole responsabilidad frente al Estado por las infracciones a la ley penal que le sean imputables. Esta inserción del menor de edad infractor en el

Pedro Nikken. «El Concepto de Derechos Humanos», en: Estudios Básicos de Derechos Humanos I. Instituto Interamericano de Derechos Humanos. T.I. San José de Costa Rica. 1994, p.26

12 Entre las garantías sustantivas podemos considerar: de culpabilidad (no pena sin culpa), de legalidad (no hay crimen ni pena sin ley previa) y de humanidad (trato humano y digno al infractor).

13 Garantías procesales contenidas en el artículo 40 de la Convención sobre los Derechos del Niño, como son: de presunción de inocencia, de defensa, de juzgamiento por un órgano judicial competente, independiente, imparcial, entre otras.

14 Garantías como son: el respeto a la privacidad del presunto adolescente infractor, y la suspensión del proceso en cualquier momento, al respecto, nuestra legislación incorpora la remisión, estando autorizados para aplicarla el Fiscal, el Juez y la Sala. Entre otras garantías, también se considera al internamiento como última medida y el cumplimiento de la medida de privación de libertad en ambientes separados a los adultos. 
ámbito penal, conllevó el reconocimiento de garantías, como escudo o resguardo que busca limitar el poder coercitivo estatal. Pero este avance en la doctrina jurídico penal trae aparejada, según Rocío Cantarero, un riesgo:

«Considerar la responsabilidad penal de los menores y jóvenes es una garantía de limitación al poder represivo del Estado. No obstante, presenta ciertos riesgos: podría ser utilizada como arma represiva desde un planteamiento más político que garantista, utilizándose el concepto de inseguridad ciudadana». ${ }^{15}$

Coincidiendo con lo indicado por la citada autora, verificamos que el D. L. No 899 creó un nuevo tipo penal, violándose el principio de legalidad, por no ser necesario, debido a la preexistencia de figuras penales que ya contenían implícitamente este supuesto del cuál derivaba una consecuencia penal. Se ha creado, en consecuencia, un nuevo tipo penal para aplicar penas más severas.

La responsabilidad penal para el adolescente infractor a la que hacemos mención, posee una naturaleza jurídica diferente a la de los adultos, ${ }^{16}$ en aras al resguardo del principio de igualdad, es decir, de brindar un tratamiento desigual a los desiguales, en este caso los adultos y adolescentes. Contrario a ello, las modificaciones introducidas con el D. L. No 899 , contienen un tratamiento normativo represivo semejante al de los adultos.

Como garantías derivadas de esta responsabilidad penal especial y en salvaguarda de la aplicación de un derecho penal mínimo, encontramos al internamiento como última medida. ${ }^{17}$ Esta garantía es explícita en la Convención, significando su incorporación la consideración de la privación de libertad como el recurso extremo y por el menor

15 Rocío Cantarero, Delincuencia Juvenil y Sociedad en Transformación. Editorial Montecorvo, S.A.

16 Como antecedente las Reglas de Beijing en su artículo 2 númeral 2.2 a) establecía "menor es todo niño o joven que, con arreglo al sistema jurídico respectivo, puede ser castigado por un delito en forma diferente a un adulto".

17 Garantía contemplada en el artículo 37.b de la Convención sobre los Derechos del Niño y en el texto del artículo 250 del Código de Niños derogado, que indicaba "La internación constituye medida privativa de la libertad, y se aplicará como último recurso por el período mínimo necesario que no excederá de tres años [...]" 
tiempo posible. Estas limitaciones, a la aplicación del internamiento, fueron una respuesta a la aplicación indiscriminada y excesiva del internamiento en las legislaciones de menores, a las que ya hicimos mención.

Para hacer efectiva esta garantía, la Convención establece la obligación de los Estados partes de considerar en las sentencias medidas alternativas al internamiento. Así, el artículo 40.4 de la Convención señala que los Estados partes deberán incorporar en su respuesta penal, la libertad vigilada, la colocación en hogares de guarda, entre otros. En base a ello el Texto Único Ordenado del Código de Niños y Adolescentes incorpora las medidas socioeducativas aplicables al adolescente infractor. Así, entonces, se trasgrede esta garantía en el capítulo correspondiente al Pandillaje Pernicioso, por sólo incorporar la internación como única medida a aplicar, justificándose implícitamente su exclusividad en la gravedad de los hechos.

A todo lo indicado debemos agregar que la finalidad de las medidas socioeducativas ha variado. En las legislaciones de menores, las «medidas de protección" aplicables a los infractores de ley tuvieron un rol de control social, bajo el discurso de la necesidad de brindar protección a aquellos menores que, debido a su entorno socioeconómico, eran proclives al crimen. A partir de la Convención sobre los Derechos del Niño, las medidas socioeducativas aplicables a los adolescentes infractores tienen un fin educador, tal como lo contempla el Art. 240 del Texto Único Ordenado del Código de Niños y Adolescentes.

Sin embargo, en el tratamiento legislativo del pandillaje pernicioso se otorga al internamiento un rol represivo. De esta manera, estamos cometiendo el mismo error, que caracterizó la aplicación de las legislaciones de menores, que buscaba suplir la ausencia de políticas sociales preventivas con una respuesta penal represiva.

Para el pandillero, tal como lo indica el texto legal, el internamiento tiene un fin rehabilitador, es decir, volver al adolescente a la situación moral o legal, en la que se encontraba, antes de la comisión del delito. Mientras que, por otro lado el fin educativo parte de considerar que el adolescente se encuentra en un período de aprendizaje, de formación, por no haber logrado interiorizar las normas sociales y jurídicas requeridas para comportarse de manera adecuada en la sociedad.

Otra garantía de la Convención, que no ha sido considerada, es el cumplimiento por separado de la privación de libertad por los adoles- 
centes y los adultos. A partir del Decreto Legislativo $\mathrm{N}^{\circ} 899$, en nuestra legislación se establece que la internación preventiva se cumplirá en el Centro de Observación y Diagnóstico del Poder Judicial, sin indicarse la obligación de recluir al adolescente en un ambiente separado al de los adultos, algo contrario, incluso, al Código de niños y adolescentes derogado, en el que se establecía explícitamente esta garantía y, adicionalmente, disponía su cumplimiento en el ente rector.

Otra modificación de importancia es que una vez cumplida la mayoría de edad, el adolescente será trasladado a ambientes especiales dentro del establecimiento penitenciario primario a cargo del INPE.

Habiendo procedido a una revisión del articulado actualmente vigente, nos resulta cuestionable que nuestra legislación contenga la responsabilidad penal especial que corresponde a los adolescentes infractores, puesto que es posible internarlo por un período prolongado y, luego de cumplida su mayoría de edad, debe abandonar el Centro Juvenil para cumplir la internación en el INPE.

\section{Propuestas para discusión}

El tema es bastante complejo, pero no queremos concluir este trabajo sin una propuesta, con la cual invitamos a la realización de una reflexión conjunta sobre cuáles podrían ser las herramientas a considerarse para dirigir nuestro accionar.

En primer lugar, debemos plantearnos preguntas como ¿qué buscamos con la ley de pandillaje pernicioso?, ¿cuál es nuestro objetivo? ¿la seguridad ciudadana? o ¿lograr la erradicación del pandillaje juvenil, a través de la inserción adecuada de los adolescentes en nuestra sociedad?

Si nuestro objetivo es la seguridad ciudadana, adoptaremos medidas corto placistas, sin una clara visión de futuro. Si nuestro objetivo es construir un país a partir de su capital humano, debemos entonces continuar nuestro análisis con una pregunta: ¿qué juventud queremos para nuestro país?, ¿qué capital humano necesitamos para alcanzar nuestro desarrollo?

Conocemos que con la dación de esta ley se ha puesto sobre el tapete temas como los problemas socioeconómicos y la criminalización de la pobreza. No nos es desconocido que los integrantes de las pan- 
dillas son los adolescentes pertenecientes a los estratos sociales con mayores carencias, son aquellos que no han logrado insertarse adecuadamente a la sociedad, debido a la falta de una igualdad de oportunidades. No es sorprendente, entonces, que aquellos que no se sienten parte de la sociedad, que no han logrado identificar con claridad qué papel juegan en la misma, tomen una postura contraria a ella, y aquí corresponde preguntarnos jes la Ley de Pandillaje Pernicioso, con la medida privilegiada del internamiento, la mejor solución para insertar a aquellos adolescentes en la sociedad?, si nuestra respuesta es negativa, se coincidirá con nosotros en que lo único que logramos con ella es reforzar la exclusión social de la que estos adolescentes ya son víctimas.

Pero entonces, ¿qué hacer? ¿dónde está la solución?. Existen muchas propuestas para terminar con esta situación, pero nos inclinamos por la orientación de programas sociales a largo plazo. Debemos comenzar a trabajar con los niños y adolescentes en su comunidad, de manera preventiva, haciéndolos participar, sentirse parte de..., sentirse parte de la sociedad, porque nadie va a destruir aquello de lo que es parte. Si respondemos adecuadamente, mediante la implementación de políticas sociales preventivas, surgirá como consecuencia natural, la seguridad ciudadana tan anhelada.

La trilogía vigente en la Convención, niño-familia-Estado, cobra en este tema, especial relevancia, debido a la corresponsabilidad del Estado y la familia, en brindar atención y respeto a los derechos del niño, la cual es recogida en el preámbulo de la Convención:

«Convencidos de que la familia, como elemento básico de la sociedad y medio natural para el crecimiento y bienestar de todos sus miembros, y en particular de los niños, debe recibir la protección y asistencia necesarias para poder asumir plenamente sus responsabilidades dentro de la comunidad».

El Estado, en consecuencia, tiene la obligación de brindar a la familia un nivel de vida adecuado para cumplir con las funciones que le son propias. La Convención cumple un rol orientador al respecto, al enfatizar el compromiso estatal de garantizar la supervivencia del niño en condiciones dignas y en resguardo de su condición de indefensión, por ser niño o adolescente. 
De esta manera, coincidiendo con las recomendaciones de Riad, debemos reconocer a la familia, como la unidad central encargada de la integración social primaria del niño, a través de un ambiente de estabilidad y bienestar, debiendo el Estado proporcionar familias sustitutas, cuando el niño o adolescente, carezca de este espacio de formación, propiciándose con ello, desde temprana edad, ese sentimiento de pertenencia, al que todo ser humano anhela.

A fin de coadyuvar en el cumplimiento de su función, debemos respaldar y fortalecer iniciativas como las de UNICEF, que con apoyo de entidades públicas y privadas, conforman Sistemas de Redes de atención al maltrato infantil (implementados en la actualidad en algunos distritos). Recordemos que una relación de violencia al interior de las familias, propicia la formación de individuos cuya interrelación con los demás siempre será violenta.

En consecuencia, la familia deberá ser la primera encargada en inculcar valores como la solidaridad, el sentido de la justicia, y en transmitir valores cristianos, no sólo a través del discurso sino, sobre todo, a través del ejemplo. La sociedad en su conjunto (esto nos involucra a todos) deberá favorecer al cumplimiento de estas funciones; nuestra actitud debe ser solidaria y consciente de la necesidad de rechazar de plano el individualismo, tan imperante en nuestra época, porque de lo contrario, nosotros seremos corresponsables de las conductas delictivas de los pandilleros. Para entender todo esto a cabalidad, deberemos responder a preguntas tales como: ¿qué tanto la imagen de los pandilleros, no es más, que un reflejo de nuestra sociedad?

A nivel comunitario, hagamos programas sociales donde los niños sean escuchados, donde sus intereses formen parte de las decisiones, donde asuman responsabilidades en los proyectos que tengan como objetivo el desarrollo de su entorno social. Bastará, por ejemplo, motivarlos y generar su participación voluntaria en el arreglo de un parque de su vecindario, o de su colegio.

En cuanto a la respuesta penal estatal actual, fortalezcamos las medidas alternativas al internamiento, eduquemos al adolescente infractor en libertad. ¿Cómo les vamos a enseñar a vivir en la sociedad y formar parte de ella si los aislamos? Creo necesario poner mayor énfasis en las medidas socioeducativas de Prestación de Servicios a la Comunidad, pero no como estamos acostumbrados a hacer las cosas (como un saludo a la bandera y nada más), sino con un plan estraté- 
gico que nos lleve a la realización de nuestra visión, la cual no ha de ser otra que propiciar mecanismos adecuados para generar en los adolescentes un compromiso con su comunidad. De manera complementaria y para finalizar podemos citar la Convención que en su artículo 40.1, establece cual debe ser la finalidad de toda respuesta penal estatal para los adolescentes que infrinjan la ley:

«[...] la importancia de promover la reintegración del niño y de que este asuma una función constructiva en la sociedad». 